\title{
An Empirical Study of Information and Communication Technology for Empowerment of Rural Women in Ghana
}

\author{
O. Adwoa Tiwaah Frimpong Kwapong \\ University of Ghana, LG 31, Legon-Accra \\ okwapong@ug.edu.gh
}

\begin{abstract}
There is a relationship between ICTs and empowerment of rural women. ICTs are applicable to all sectors of development for women, most especially education, livelihoods, healthcare and government which are directly linked to poverty alleviation. Meanwhile there are arguments that tight fiscal constraints facing Ghana may frustrate the widespread use of ICT by households. This is especially troublesome in the case of poor rural female households because without some type of government assistance, the ICT revolution may escape them altogether. Most scholars and policy leaders recognize that ICT is one of the contributing factors to social and economic disparities across different social and economic groups, for example, disparities between developed and developing countries, between rural and urban dwellers, and between men and women. The critical information needed for making appropriate and relevant ICT policies to improve rural conditions for women is to identify the characteristics of rural female households, and how these characteristics influence the choice of ICT technology.

The study uses results from a survey of $\mathbf{1 0 0 0}$ households from the ten regions in Ghana to assess rural female household heads' willingness to pay for alternative ICT use in the delivery of information to them. A pooled cross section technique was used to estimate an aggregate technology choice function for the entire country. Among the principal factors in the empirical model were households' incomes, levels of education, sizes of households, availability of cooperatives or community organizations, age, and marital status. Standard regression techniques that correct for possible heteroscedastic errors due to the differences in regional and households' attributes were used to estimate the model.
\end{abstract}

The results of the study leads to a need to set rural empowerment policies and programs within the broader poverty reduction policies of the government and also within the attainment of the Millennium Development Goals (MDGs). The results enforce that the attainment of the MDGs would boost ICT use in delivering information to rural households since income was found to be consistently statistically significant in explaining rural women's willingness to pay for information. Considering the context of the relationship between incomes and ICT use to empower rural women the key issue is for policy and program planners to better understand the dynamics in the enterprises of rural women and to recognize shifts in economic activity that may be counter to the historical pattern of economic activity which is agriculture oriented and design programs that will respond adequately to such shifts. By so doing rural women will be in a good position to utilize the full potential of ICT which will in turn improve their productivity/income and facilitate their empowerment.

Index Terms-Rural women, ICT, radio, extension agent, farmers

\section{INTRODUCTION}

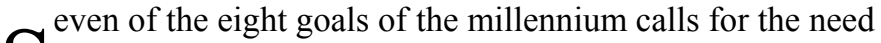
to design policies and programs that will help improve the overall well-being of women in society. The poverty reduction program of Ghana projects the issues of women for policy initiatives because as observed by [1], "gender disparities are prevalent in Ghana and closing the gender gap and enhancing women's participation in development is essential not only for building a just society, but is also a prerequisite for achieving political, social, economic, cultural and environmental security among people on a sustainable basis" (Pg. 33). Both the MDGs and Ghana's Poverty Reduction Strategy Program (GPRP) emphasize women's empowerment as a goal to address the problem of poverty [2]. The two instruments raise issues about the content of empowerment programs and how development workers could obtain the participation of the target group in designing and implementing empowerment programs. Concerning the issue of content, the literature suggests that information is the key ingredient in designing women's empowerment programs while information and communication technologies (ICTs) on the other hand could serve as both a delivery mechanism and an interactive media for obtaining the participation of the target group.

\section{PROBLEM STATEMENT AND OBJECTIVES}

Ghana responded to the ICT challenge in the 2003 for implementation of the Ghana Integrated ICT for Accelerated Development (ICT4AD) Policy [3]. Several laws and policy initiatives have been introduced in support of Ghana's ICT policy. These include the National Initiative Concerning the ICT and Education and Training, the African Information Society Initiative, and the Science and Technology Policy Research Institute. Despite these efforts, there are several problems affecting the ICT sector. First ICT policy planning and implementation is spread among several ministries, institutes, research centers, and private agencies. This increases the potential for conflicts and duplication of effort. There are concerns that the uneven access to education would translate to a 'gender digital divide' in Ghana unless explicit and credible policies are put in place to address the situation. There are also problems in making ICT available to a large segment of the population, especially for educational purposes in the rural areas due to lack of appropriate infrastructure. 
One way to address these shortcomings is to design and implement ICT programs that are consistent with the socioeconomic status and characteristics of users. It is important to understand how much ICT users are willing to pay for alternative ICT delivery technologies to better design policies.

The overall objective of this study was to identify and assess alternative ICT strategies for empowering rural women in Ghana. The study uses results from a survey of 1000 households from the ten regions in Ghana to assess rural households' willingness to pay for alternative ICT use in the delivery of information to households.

\section{LITERATURE REVIEW}

Literature on ICT, women especially in developing countries and other related issues have been reviewed to explore the potential of ICT for empowering rural women and the issues associated with it. Some cases from South Africa and Uganda have also been provided as evidence to the possibility of supporting rural women with ICT.

\section{A. ICT for Empowerment of Women}

Access to information has become one of the discriminating factors between the rich and the poor communities and the marginalized in the world. There is growing revolution of information that is fundamentally transforming the way in which businesses, citizens and governments operate and interact. Access to information and usage of information and communication technology (ICT) facilities is worse for women than men. Gender divide is one of the most significant inequalities to be amplified by the digital revolution which cuts across all social and income groups. The situation is worse for women in Africa and most especially those from rural communities. In most parts of Africa, women users are part of a small, educated urban elite. Low levels of education and illiteracy, reinforced by poverty, account in large measure for the problems African women face in accessing and using ICTs. Meanwhile ICTs offer immense possibilities for reducing poverty, overcoming women's isolation, giving women a voice, improving governance and advancing gender equality. This makes the need to make ICT accessible to all most especially women in rural communities a critical issue [4]-[5].

Empowerment of women is a process of enhancing women's capabilities to make them independent individuals. The empowerment of women concerns women gaining power and control over their own lives. It involves awarenessraising, building self-confidence, expansion of choices, increased access to and control over resources and actions to transform the structures and institutions which reinforce and perpetuate gender discrimination and inequality [6]. Promoting the cause of women will not only achieve the third goal of the millennium but its also a key to reducing child mortality, achieving universal primary education, improving maternal health, combating HIV/AIDs, malaria and other diseases and ensuring environmental sustainability. Thus almost all the millennium development goals relate to the empowerment of women. This makes it crucial to explore various ways of working towards enhancing women's capabilities. The fast growth in development of ICT is leading to production of easily accessible and cost effective protocols that could serve all including women in endowed and underserved localities and most importantly its ability to create opportunities for bridging the poverty gap.

Information and communication technologies can be interpreted broadly as technologies that facilitate communication and the processing and transmission of information by electronic means. This definition encompasses the full range of ICTs, from radio and television to telephones (fixed and mobile), computers and the internet [5].

The internet protocol, broadband technology and wireless connection offer great opportunities for development. They are especially valuable to people with reduced or negligible access to healthcare, government, education services and other facilities such as rural women. They help to bridge the telephonic divide between the rich and the poor.

The flexibility of mobiles is also seen to be more conducive to micro enterprise - especially in rural and suburban areas [7].

ICTs are applicable to all sectors of development for women, most especially education, livelihoods, healthcare and government which are directly linked to poverty alleviation. Five of the eight MDGs focus on these sectors, which attract a lot of focus in discussions on ICT and poverty alleviation. [8] notes that since the 1990s, there have been several initiatives around the globe to apply ICT to address issues of poverty in developing countries. His study found a positive correlation between investment in ICTs and economic growth. The study also shows that information leads to resources and opportunities that generate more resources. Several empirical studies cited by [8] have established the relationship between just the telephone and economic growth. In a study by Centre for Economic Research in UK [8], it was found that a developing country with an average of 10 mobile phones per 100 population between 1996 and 2003 had a per capita GDP growth of more than 0.59 percent higher than an identical country. Another study also describes how the clockwork radio has been used in South Africa for the rural people to listen to development programs, community education programs and disaster relief efforts. They have been used for broadcasts on weather, health issues, and government policies in Mozambique. To further prove the point that the use of ICT can contribute to poverty alleviation, [8] undertook a study to demonstrate empirically the association between ICT and incidence of poverty using data from Uganda. The results of Ssewanyana's empirical study shows that households without ICT are more likely to be poor relative to their counterparts with ICT. Thus a combination of ICTs with improved education levels is associated with lower incidence of poverty. When ICTs are well utilized, they can expand people's income through better market information, good weather forecasts, agricultural and health advice. It should be emphasized here that ICT alone cannot alleviate poverty, it has to be accompanied by improvements in other development areas such as transport, health, education, gender relations, and other socio-cultural influences. The case on deployment of an e-commerce platform in Rural South Africa indicates 
how ICT has been used to empower underserved women in particular.

\section{B. Cases of Rural Women in South Africa and Uganda}

[9] report that an e-commerce platform which can make a contribution to rural development and poverty alleviation was implemented in Dwesa, a rural community in South Africa. Like many rural areas, Dwesa is characterized by lack of infrastructure in terms of road and electricity, widespread poverty, lack of services and isolation which facilitate migration of the youth to cities. The areas where Dwesa has most to offer are tourism, arts and crafts. An ICT system was designed to promote tourism and advertise local arts, crafts and music. In the project deployment of infrastructure, technical support, promotion of the initiative and teaching of computer literacy took place during monthly visits of approximately one week, and involved young researchers from two universities to ensure a synergy between technical expertise and understanding of the local context. Teachers were trained to promote computer literacy in the school and in the community.

The novelty of the approach was its sensitivity to the context and its emphasis on the promotion of active participation of the community and sustainability. The authors add that the platform is being extended to e-government, elearning and e-health capabilities. The model could be exported to similar areas in South Africa and in the rest of Africa which could open up potential opportunities for the still unexplored market for ICT in rural Africa.

Under its, Information Sharing and Networking programme, Women of Uganda Network (WOUGNET) undertakes a project on 'Enhancing Access to Agricultural Information using ICTs (EAAI) in Apac District'. The project was initiated in 2005 to develop and improve information and communication systems so as to enable easy access to agricultural information for rural women farmers. This was based on an initial research finding that lack of information was a key limiting factor to increased productivity in Apac District. The rural farmers lacked information on how to improve quality of their products, improved seeds and crop varieties, source of inputs/implements, plant diseases, pests and their control, soil management and conservation, and improved skills. Lack of such information had limited the production levels of the rural farmers, hence limited income and poverty. The EAAI project was therefore implemented in twelve parishes/villages and counties in Apac District. The project targets grassroot women farmers as the main beneficiaries while not excluding men or the youth in the project activities.

Local agricultural content has been produced and disseminated via radio and SMS messages as well as on audiotapes, video tapes and CD-ROMs. The content is made available in the local language, Luo, and disseminated to farmers. In order to ensure timely dissemination of relevant information to farmers, the EAAI project has applied a number of collaborative strategies such as teaming up with a rural radio in Apac to ensure delivery of information that is packaged, transcribed and formatted into a series of weekly radio programs. Existing sources of agricultural information including Agency for Sustainable Development Initiatives (ASDIii), Radio and Internet Programme (RANET) - Uganda, Metrological Department, and the Apac District Agricultural Office are all collaborators.

For interaction and feedback, question and answer arrangement is available to assist farmers in providing a technical back up. The project also seeks to use the Internet to bridge the gap between researchers, extension workers and the farmers. Though there are constraints, lessons from the project has revealed that access to information, knowledge and skills are key enablers for the socio-economic emancipation of both urban and rural women [10].

The two cases from Uganda and South Africa have shown how information has been packaged and delivered to rural women mostly in agriculture which is the major economic activity among rural folk in Africa. New farming practices, post-harvest technologies, food processing technique and marketing strategies are crucial for rural female farmers. Upto-date information on such areas will no doubt boost their productivity and as a result reduce poverty among them.

\section{The ICT Situation in Ghana}

Ghana has set a vision to achieve middle-income status by the year 2020. This vision is embedded in the country's Millennium Development Goals (MDGs) and its Poverty Reduction Strategy Program (PRSP I\&II) [11]. There are strong indications that Ghana will be able to meet the MDGs with effective policies that target poverty alleviation. The real gross domestic product (GDP) growth has averaged about 5 percent since 1983, and overall poverty has declined from 52 percent in 1992 to 28 percent in 2006 [12]. While the debate on appropriate strategies to push the development agenda has focused on the availability of the traditional factors of production - land, labor, and capital, there is an emerging consensus that the efficient use of ICT could be indispensable to any credible effort to turn the corner towards higher levels of growth and improvement in the human condition [13]. Professor Allotey first raised the alarm that, "we paid the price of not taking part in the Industrial Revolution ...because we did not have the opportunity to see what was taking place in Europe. Now we see that information and communication technology (ICT) has become an indispensable tool. This time we should not miss out on this technological revolution" [14].

The core of the country's development agenda is poverty alleviation and improvement in the socio-economic well-being of people in rural and urban areas. With improvements in ICT, it is possible to design and manage a policy that makes it possible to introduce information to empower the strategic groups such as women in the rural and urban areas. The government recognizes this opportunity and has succinctly stated that Ghana's ICT development goal is to develop an ICT-driven socio-economic development policy and plan that will aid Ghana's developmental effort and move the economy and society towards a knowledge-based information society and economy in the shortest possible time [15]. As a result of these initiatives, there have been increase in ICT resources in 
the country. Main telephone lines in use are 356,400; mobile cellular is 5.207 million, radio broadcast stations is AM $0, \mathrm{FM}$ 49 , and shortwave 3 ; television broadcast stations are 7; internet hosts are 2,899 and internet users are estimated at 609,800 [16]. A nationwide project is currently ongoing to wire the entire country.

Despite the important role of ICT for development in Ghana, there are concerns that tight fiscal constraints facing Ghana may frustrate the widespread use of ICT by households. This is especially troublesome in the case of poor rural households because without some type of government assistance, the ICT revolution may escape them altogether. There are also conflicting views on using ICT for sustainable development in a developing country especially for rural women which affects policy direction in Ghana. Some have argued that developing countries such as Ghana should focus on the more immediate and pressing needs such as jobs, food, water, education, and electricity instead of ICT development that requires considerable expenditure of scarce resources [17]. Others have argued in support of a full exploration of the use of ICT as a tool for attacking the difficult problem of poverty alleviation [17]-[18]. In the face of these conflicting views, what most scholars and policy leaders agree on is the recognition that ICT is one of the contributing factors to social and economic disparities across different social and economic groups, for example, disparities between developed and developing countries, between rural and urban dwellers, and between men and women. The consensus is based on observations on current ICT use around the world. For example, it has been estimated that the total number of African Internet users are around 5-8 million, with about 1.52.5 million outside North and South Africa. This is about 1 user for every $250-400$ people, compared to a world average of about one user for every 15 people, and a North American and European average of about one in every 2 people [18].

The critical information needed for making appropriate and relevant ICT policies to improve rural conditions is to identify the characteristics of rural female households, and how these characteristics influence the choice of ICT technology.

\section{MODEL, METHODOLOGY AND STATISTICAL ESTIMATION}

A model explaining the relationship between information technologies, rural households' information use that leads to women's empowerment must at a minimum address five important issues. These include the process of information technology policy formation and implementation, alternative information delivery technologies recognizing the cost and sustainability implications of the alternatives, a recognition that rural women's choice of information technology is not only a technical issue but more importantly it depends on the socio-economic characteristics of the women, especially in willingness and ability to pay for the technology, selected indices that are general enough to capture the broad meaning of the concept of 'empowerment among women', and a feedback loop that highlights the critical role of information in the learning and interaction process. This last characteristic of the framework emphasizes the need to treat information availability and decision-making as an ongoing process, and not a one-shot discrete event that is unrelated to the future choices made by rural women.

The data used in this study was based on a contingent valuation survey instrument developed and administered in several villages in the ten regions in Ghana. The survey was divided into two main parts. The first part sought information on basic characteristics of households (age, education, dependents, occupation, expenditures, and membership in community organizations). The second part consisted of a bidding game for alternative information delivery technologies. Three main information delivery technologies were considered - community radio, private radio, and extension agent (printed material). The main distinguishing feature of these technologies was price. For example, information delivery by community radio was considered the cheapest since several households contribute to the purchase and maintenance of the system. Extension agents were the next cheapest of the three technologies considered because the government pays these agents. The idea was to explore the extent to which a part of the cost of extension information delivery could be shifted to households and lessen the burden on government. The most extensive delivery technology was the private radio since a household owns it individually and pays full amount for it.

Bidding took the form of a series of specific questions. For example, a respondent was asked whether she would be willing to pay $\mathrm{GH} \phi 0.10$ (approx. US0.10) per year to use a community radio. If the response was 'yes' the question was posed again with an increase in the amount to $\mathrm{GH} \phi 0.20$ (approx. US0.20). The process continued until a 'No' answer. The final amount to which the respondent answered 'yes' was recorded as the maximum willingness to pay to have the community radio installed in the village. For extension agents, the beginning bid was at $\mathrm{GH} \phi 0.50$ (approx. US0.50), while for private radios, the beginning point was $\mathrm{GH} \phi 1.00$ (approx. US1.00). Respondents were also asked to state an amount they were willing to pay for each of the information delivery technologies.

Data collection was a face-to-face interview where the interviewer had the opportunity to explain the purpose of the survey and the need to obtain truthful responses from the respondent. There was no known sampling frame for the rural areas and no attempt was made to create a sample frame for the localities. The interviewers were quite familiar with the villages and based on their experiences understood the need to interview in a manner that did not impair the integrity of the effort. For example, respondents were cautioned not to discuss their responses with other households. There was broad agreement among field staff that respondents took the process seriously and were willing to offer truthful information to assist in achieving the objectives of the survey.

The survey data was estimated using a multiple linear regression statistical model of the form:

$(\mathrm{WTP})_{\mathrm{ijt}}=\mathrm{a}_{0}+\mathrm{a}_{1}($ AGE $)+\mathrm{a}_{2}($ EDUC $)+\mathrm{a}_{3}($ MARS $)+\mathrm{a}_{4}$ $($ DEPEND $)+\mathrm{a}_{5}($ EXPEND $)+\mathrm{a}_{6}($ MEMBR $)+\mathrm{U}_{\mathrm{i}}$, 
where (WTP) $)_{\mathrm{ijt}}$ is the willingness to pay by a household (i) in region (j) for information delivery technology (t), AGE is age of respondent measured in years, EDUC is the educational level of respondent. MARS was the marital status of respondent, and was measured using a dummy variable equal to 1 if respondent is married, and zero if otherwise. DEPEND is the number of dependents of respondent, EXPEND is the aggregate of all expenditures reported by the respondent measured in Ghanaian Cedis, and MEMBR is the membership of respondent in a community organization. Membership was measured as a dummy variable, equal to 1 if the respondent belonged to a community organization and zero, if otherwise. The term $U$ is a random error term assumed $\mathrm{N}\left(0, \sigma^{2}\right)$.

\section{V.RESULTS}

Results on the socio-economic characteristics of respondents revealed that $94 \%$ of the women fell within the active adult stage of $21-50$ years; $70 \%$ of the household heads were married; $45 \%$ of the household heads had no formal education; only $11.2 \%$ had no regular source of income; a sizeable figure, $62.4 \%$ of the women indicated that apart from their regular jobs, they had other sources of income; majority of the women $(45.8 \%)$ reported trading as the primary source of income while $23.9 \%$ reported farming as their primary source of income, $7.7 \%$ reported dressmaking as their primary source of income while $4.1 \%, 2.7 \%, 2.6 \%$ reported hairdressing, teaching, and office work respectively as the primary source of income, sizable percentage (11.2\%) reported no income source; $50.3 \%$ of the rural women were members of women's groups and cooperatives; a higher percentage of 72.5 indicated their desire to acquire information and skills.

Table 1 lists the means of selected independent variables for the ten regions in the study, and the mean bids for extension services, community radio, and private radio. Mean household size and expenditures are also provided. Consistent with expectation, mean bids for private radio is highest, followed by mean bids for extension information, followed by community radio.

TABLE 1. MEANS OF INDEPENDENT VARIABLES COMPARED to MEANS FROM GLSS 4

Source: Survey and GLSS 4, Table 9.2

\begin{tabular}{|c|c|c|c|c|c|c|}
\hline & \multicolumn{3}{|c|}{ Household Bids in } & \multicolumn{3}{|c|}{} \\
\hline Region & $\begin{array}{c}\text { Exten- } \\
\text { Sion } \\
\text { Infor- } \\
\text { mation }\end{array}$ & $\begin{array}{c}\text { Comm- } \\
\text { unity } \\
\text { Radio }\end{array}$ & $\begin{array}{c}\text { Priv- } \\
\text { ate } \\
\text { Radio }\end{array}$ & $\begin{array}{c}\text { No. of } \\
\text { Dep- } \\
\text { en- } \\
\text { dents }\end{array}$ & $\begin{array}{c}\text { Expen- } \\
\text { diture } \\
\text { Survey }\end{array}$ & $\begin{array}{c}\text { Expen- } \\
\text { diture } \\
\text { GLSS 4 }\end{array}$ \\
\hline Western & 6182 & 3535.5 & 10404 & 2.79 & $5,0525,25$ & $4,677,000$ \\
\hline Ashanti & 8480 & 3360 & 22300 & 3.61 & 11054650 & $5,008,000$ \\
\hline B. Ahafo & 10030 & 3730 & 24305 & 1.77 & $4,180,710$ & $3,544,000$ \\
\hline Central & 10180 & 3886 & 22450 & 3.74 & $5,153,510$ & $2,977,000$ \\
\hline Eastern & 8909 & 4868 & 22696 & 3.33 & $8,549,222$ & $3,736,000$ \\
\hline G. Accra & 10202 & 3656 & 21162 & 2.83 & $11,495,48$ & $6,777,000$ \\
\hline Northern & 9520 & 3400 & 21069 & 4.43 & $3,335,400$ & $2,837,000$ \\
\hline Up. East & 8595 & 3141 & 21262 & 3.04 & $4,059,460$ & $1,793,000$ \\
\hline Up. West & 9980 & 3830 & 26200 & 5.67 & $2,070,160$ & $2,462,000$ \\
\hline Volta & 7320 & 5200 & 11190 & 2.39 & $6,134,540$ & $4,000,000$ \\
\hline
\end{tabular}

Mean expenditure pattern for households also tracks the numbers from GLSS 4 [19]. However, in Greater Accra, Eastern, and Central regions, means from the survey are significantly different from the means based on GLSS 4 . Since the GLSS 4 is based on 1999 information, it could be that expenditures have changed significantly over the last five years. The means are sufficiently credible to provide a reasonable basis for the survey data analysis.

Equation 1 was estimated for all regions combined and then for each individual region using the Newey-West estimator. This estimation technique helps to address one of the common problems when one uses cross-section data. The socioeconomic characteristics of households differ in important ways so unless the statistical procedure takes into account these variations, the estimated coefficients may not be efficient due to problems of heteroskedasticity and autocorrelation. The Newey-West estimation procedure takes into account the problems in using cross-section data to give consistent and efficient estimates. The results of the estimation procedures are presented below.

Tables $2 \mathrm{a}, 2 \mathrm{~b}$, and $2 \mathrm{c}$ present the results of regression analysis using the combined data set for all regions. Four observations were rejected so the total number of observations was 996 instead of 1000 ( 100 observations for each of the 10 regions). The overall explanatory power of the model was poor with an $\mathrm{R}^{2}$ (Coefficient of determination) of $7.5 \%$ for the community radio regression, $6.9 \%$ for private radio and $8.4 \%$ for extension services. The low explanatory power of the models was consistent with what one would expect in regression analysis using cross-section data. Furthermore, there was statistical significance of several of the critical socioeconomic factors that were hypothesized to influence rural women's' willingness to pay for selected information delivery technologies.

Table 2a shows that older women, educated above the primary school level, with high expenditure levels, and were members of a community organization were more willing to pay for information delivered via a community radio. With the exception of the income factor that was statistically significant at the $10 \%$ level, all the other factors were significant at the $1 \%$ and $5 \%$ levels. The table also shows that younger women (below age 20) were not willing to pay for information delivered via a community radio. Results for information delivered via private radio (Table $2 \mathrm{~b}$ ) follow the 
pattern obtained for community radio but it is also found that married women were willing to pay for information delivered via private radio. This may be due to the fact that married households have higher income (combined income) and could afford the more expensive media for information delivery.

This observation is supported by the fact that the estimated coefficient for expenditures (.00011) in Table $2 \mathrm{~b}$ is bigger than the estimated coefficient for expenditures $(5.09 \mathrm{E}-06)$ in Table 2a. Also the expenditure factor in Table $2 \mathrm{~b}$ is highly significant (1\% level) compared to the significance level (5\%) for the same factor in Table 2a. Table 2c reports the results of estimation for information delivered via extension agents. The pattern observed under the two previous results is observed for information delivery via extension agents. Here again, the principal factors were high education, high expenditures, membership in community organizations, age and marital status. The results show that younger women were not willing to pay for information delivered via extension agents. The only factor that was not found significant in explaining variation in the choice of information media was the number of dependents.

$$
\text { TABLE2A }
$$

REGRESSION RESULTS FOR HOUSEHOLDS WILLINGNESS TO PAY FOR COMMUNITY RADIO

\begin{tabular}{lll} 
Variable & Coefficient & t-Statistic \\
\hline \hline Constant & 3017.98 & 23.08 \\
Age [Up to 20] & -704.62 & -5.07 \\
Age [Above 20] & 180.84 & 2.69 \\
Married & 38.70 & 0.43 \\
Dependents & -1.60 & -0.10 \\
Educ. [Primary] & -110.71 & -0.84 \\
Educ. [Above Primary] & 187.74 & 2.05 \\
Expenditure & $5.09 \mathrm{E}-06$ & 1.62 \\
Membership & 316.90 & 3.54 \\
\hline \hline R-squared & 0.075 & $\mathrm{~N}=996$
\end{tabular}

\section{TABLE2B}

REGRESSION RESULTS FOR HOUSEHOLDS WILLINGNESS TO PAY FOR PRIVATE RADIO Variable Coefficient t-Statistic

\begin{tabular}{lll}
\hline \hline Constant & 12333.05 & 8.14 \\
Age [Up to 20] & -5469.63 & -2.54 \\
Age [Above 20] & 1041.34 & 0.81 \\
Married & 3433.88 & 2.47 \\
Dependents & 348.89 & 1.40 \\
Educ. [Primary] & 1204.46 & 0.73 \\
Educ. [Above Primary] & 5663.57 & 3.17 \\
Expenditure & 0.00011 & 2.82 \\
Membership & 4867.08 & 3.69 \\
\hline \hline R-squared & 0.069 & $\mathrm{~N}=996$
\end{tabular}

TABLE2C

REGRESSION RESULTS FOR HOUSEHOLDS WILLINGNESS TO PAY FOR EXTENSION OFFICER Variable Coefficient t-Statistic

\begin{tabular}{lll} 
Constant & 6707.23 & 17.23 \\
Age [Up to 20] & -1855.98 & -4.57 \\
Age [Above 20] & 395.12 & 1.95 \\
Married & 463.64 & 1.71 \\
Dependents & 48.58 & 1.059 \\
Educ. [Primary] & -27.67 & -0.089 \\
Educ. [Above Primary] & 473.32 & 1.82 \\
Expenditure & $1.43 \mathrm{E}-05$ & 2.22 \\
Membership & 1298.57 & 5.20 \\
\hline \hline R-squared & 0.084 & $\mathrm{~N}=996$
\end{tabular}

\section{CONCLUSION AND POLICY RECOMMENDATIONS}

From the results of the study it could be concluded that using ICT for empowerment of rural women should not be perceived narrowly but in a much broader development perspective. This is in recognition of the fact that it is not only one socio-economic factor that came up as a major determining factor in the choice of ICT. Similarly no single information delivery technology emerged as the core technology to use in delivering information to rural women. Different socio-economic factors - income, education, age, and membership of a community organization were found to be significant and different media appealed to different respondents. As a result one could emphasize that there is the need to set up rural empowerment policies and programs within the broader poverty reduction policies of the government and also within the attainment of the Millennium Development Goals (MDGs). This way we will be working towards total empowerment of all rural women. Since income was found to be consistently statistically significant in explaining rural women's willingness to pay for information the results enforce that the attainment of the MDGs would boost ICT use in delivering information to rural households. The income factor plays a dual role in the use of ICT for empowerment of rural women. While high income levels could make it possible for rural women to pay for the information delivery technology of choice, the information they obtain will in turn equip them with adequate knowledge that will be possibly ploughed into their economic activities and for that matter improve their income generation and status [20]-[21].

The relative high significance of the income factor should draw attention to the necessity of undertaking interventions that will capture the broadening base of rural women's enterprises. The first part of the survey on the socio-economic characteristics of the respondents revealed that as high as $45.8 \%$ reported trading as the primary source of income while $23.9 \%$ reported farming as their primary source of income. Other income sources were dressmaking, hairdressing, teaching and office work. This could explain why several households were not willing to pay for information delivered by extension agents who mainly deliver agriculture-related information but rather radios which deliver information that complement activities as hairdressing, dressmaking, office work, and trading. An understanding of growing job 
dynamics in the rural sector could help outline policies and programs and deliver information that will respond to the changing job needs.

\section{REFERENCES}

[1] M. Awumbila, "Women and Gender Equality in Ghana: a Situational Analysis" in D. Dsikata, Ed. Gender Training In Ghana - Politics, Issues and Tools. Ghana: Woeli Publishing Services, 2001.

[2] Ghana Poverty Reduction Strategy 2003 -2005 - An Agenda for Growth and Prosperity, 2003.

[3] Ghana, "Republic of Ghana - National ICT Policy and Plan Development Committee", 2003.

[4] J. Daly, "ICT, gender equality and empowering women", Retrieved March 20, 2008 from http://topics.developmentgateway.org/ict/sdm/previewDocu ment.do $\sim$ activeDocumentId=622821. 2003.

[5] UNESCO, "Towards a more equitable information society: How and why of gender mainstreaming", Retrieved March 21, 2008 from

http://portal.unesco.org/ci/en/file download.php/250561f24 133814c18284feedc30bb5egender issues.pdf. 2003.

[6] UN, "Women watch fact sheet", Retrieved August 15,2008 from http://www.un.org/womenwatch/osagi/pdf/factsheet2.pdf, August 2001.

[7] Maplecroft, "Information and communication technology: 2006 - 2008", Retrieved May 11, 2008 from http://forum.maplecroft.com/loadmap?template=map.

[8] J. K. Ssewanyana, "ICT access and poverty in Uganda", International Journal of Computing and ICT Research., vol. 1 no. 2, pp. 10 - 19, June, 2007.

[9] L. Dalvit, M. Thinyane, H. Muyingi, and A. Terzoli, "The deployment of an e-commerce platform and related projects in a rural area in South Africa" International Journal of Computing and ICT

Research, vol. 1 no.1, pp. 9 - 18, June, 2007.

[10] D. Women of Uganda Network initiative Retrieved August 15, 2008 from http://www.i4donline.net/articles/currentarticle. asp? articleid=2042\&typ=Features, July 2008.

[11] Ghana, "Ghana poverty reduction strategy 2003 -2005 An agenda for growth and prosperity", Retrieved February 16, 2008 from http://poverty.worldbank.org/files/Ghana_PRSP.pdf., 2003.

[12] World Bank, "The little data book on information and communication Technology", 2007.

[13] O. A. T. F. Kwapong, "Policy implications for using ICTs for empowerment of rural women in Ghana", The Turkish Online Journal of Educational Technology - TOJET, vol. 7, no.3, July 2008.

[14] R. A. Opoku, "ICT opportunities in Ghana-A lesson for the Government and Ghanaian entrepreneurs" Retrieved
June 20, 2008 from http://www.ghanaweb.com/GhanaHomePage/features/artikel.p hp? ID=49218, 2004.

[15] Ghana, "Republic of Ghana - National ICT policy and plan development committee", Retrieved March 31, 2008 from

http://www.ict.gov.gh/html/Landscape $\% 20$ of $\% 20 I C T \% 2$ 0Human $\% 20$ Resources $\% 20 \& \% 20$ Expertise $\% 20 . \mathrm{htm})$, 2004.

[16] Infoplease, “Ghana” Retrieved March 10, 2008 from http://www.infoplease.com/ipa/A0107584.html, n.d.

[17] S. Gulati, "Technology-enhanced learning in developing nations: A review", TheInternational Review of Research in Open and Distance Learning, vol. 9, no.1, 2008.

[18] A. Abdulkafi, "The internet in developing countries: A medium of economic, cultural and political domination, International Journal of Education and Development using ICT, vol. 4, no. 1, 2008.

[18] ITU, "United Nations conference on trade and development - Beyond WSIS: World Information Society report", 2007.

[19] GLSS 4, "Ghana Living Standards Survey - Report of the Fourth Round", Ghana Statistical Service, 2000.

[20] O.A.T.F. Kwapong, "Exploring Innovative Approaches for Using ICT for Rural Women's Adult Education in Ghana", Ghana Journal of Development Studies Vol. 2 No. 2, pp. 30-41, December, 2005.

[21] B. Robinson, "Using distance education and ICT to improve access, equity and the quality in rural teachers' professional development in western China", The International Review of Research in Open and Distance Learning, vol. 9, no. 1, 2008.

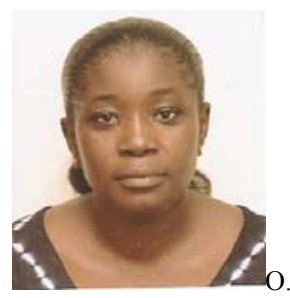

O. Adwoa Tiwaah Frimpong Kwapong $(\mathrm{PhD})$ is a lecturer at the Institute of Adult Education, University of Ghana. She has studied as a Special $(\mathrm{PhD})$ student at Harvard University. Her areas of expertise are participatory adult learning, gender analysis, technologymediated learning, open and distance learning, and community mobilization. She consults for both governmental and non-governmental organizations. 